\title{
iPad Mapping Applications: Evaluation and Workflow
}

Dr. Arthur B. Busbey, School of Geology, Energy, and the Environment TCU, Fort Worth, Texas 76110; a.busbey@tcu.edu

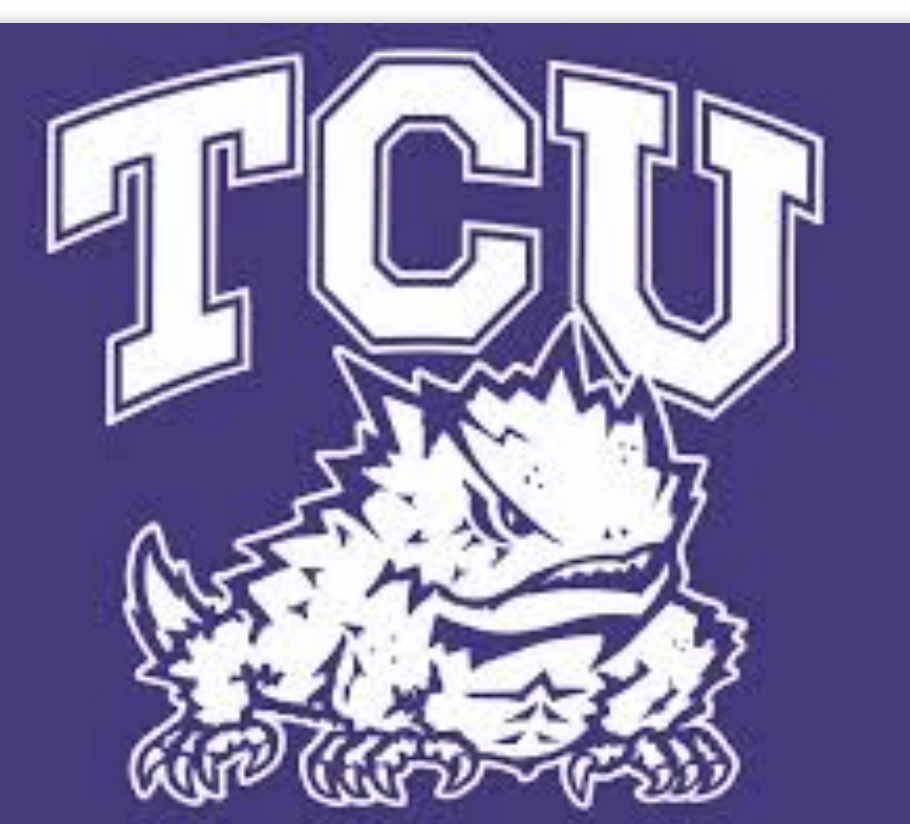

Disclaimer: Any inaccuracies in features or costs are my fault and are not intentional.

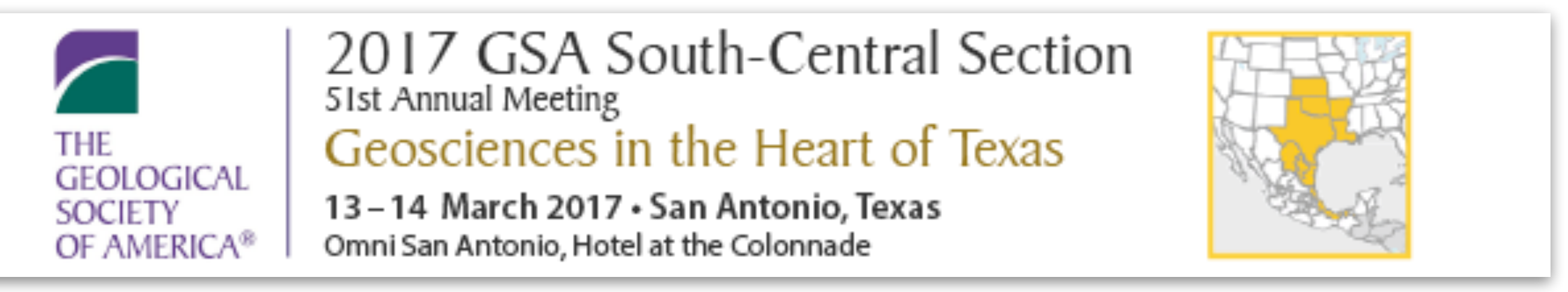




\section{iPad Field Use}

- Cached and/or Custom data for offline

- Battery longevity; charge anywhere there is a powered USB port

- GPS/GLONASS in cellular models and available as plugin or bluetooth modules for wifi-only models (Dual XGPS150, GNS $8570 \mathrm{MFI}$, Garmin GLO GPS)

- Ease of back up

- Onboard magnetometer, gyroscope and accelerometer

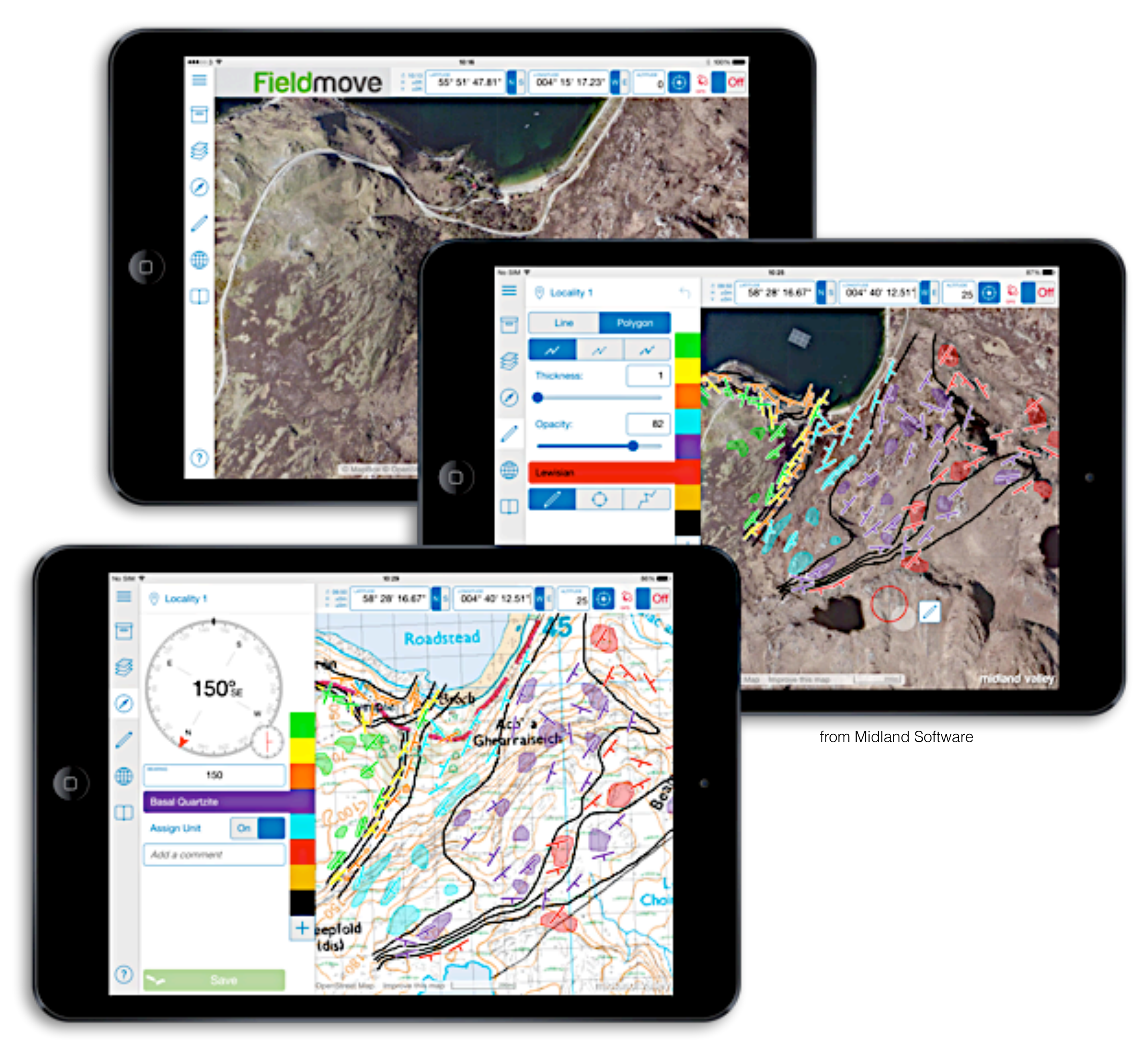




\section{iPad Field Work: To Consider...}

- Size - iPad Pro (12.9 inch) seems to be too large to be comfortable in the field, but the iPad (9.7 inch) and iPad Mini (7.9 inch) work very well.

- Fragility - use a mil-spec field case to protect from dust, moisture and impacts and carry case in pouch

- Battery - need to practice active conservation (Airplane Mode) - auxiliary battery charger

- Glare - screen can be difficult to read at times

- Thermal load - keep temperature within limits - hot end try to keep in shade

- Export projects or data when possible:

- hybrid USB/Lightning storage

- email - requires Cellular or Wifi connection

- iTunes sync

- When possible and if appropriate transfer contacts and points to paper maps 


\section{iPad Field Use Applications}

- iHikeGPS, Topo Maps - Display cached USGS too maps and store waypoints, tracks, etc., after apps purchased all downloads free

- Gaia GPS, GaiaPro - Display wide variety of online maps that can be locally cached for field work

- iGIS HD - GIS, import and export ArcInfo Shapefiles, cache custom maps

- Lambert - Collect geological control information

- FlightLine - View cached low-res geology

- Scenic View W,C,E - View synthetic cached or online 2D/3D satellite image maps with topography, roads, place names, etc.

- Geofieldbook, FieldMove, FieldMove Clino - geologic field mapping tools

- MapTiler (Windows or Mac) - Georectify maps/images and translate into KML, MBTiles and other formats 


\section{Comparison of some Applications}

\begin{tabular}{|c|c|c|c|c|c|c|c|c|}
\hline & Map Data & Waypoints/paths & $\begin{array}{c}\text { Strike/Dip } \\
\text { Bearing/Plunge }\end{array}$ & Stereonets & Formations & Images & Notes & Export \\
\hline iHike GPS & $\begin{array}{l}\text { Cache USGS GeoTIFFs } \\
\text { and/or U.S. For. Srv. Maps }\end{array}$ & Import/Export & & & & & $\begin{array}{l}\text { Attached to } \\
\text { waypoints }\end{array}$ & GPX \\
\hline Topo Maps & Cache USGS GeoTIFFs & Import/Export & & & & & $\begin{array}{l}\text { Attached to } \\
\text { waypoints }\end{array}$ & GPX, .kml, .csv \\
\hline GAIA GPS & $\begin{array}{l}\text { Cached Online or user imported } \\
\text { TMS service } \\
\text { Pro version has many more } \\
\text { online maps available }\end{array}$ & Import/Export & & & & & $\begin{array}{l}\text { Attached to } \\
\text { waypoints }\end{array}$ & GPX, .kml \\
\hline Lambert & $\begin{array}{l}\text { Only online Apple Maps and } \\
\text { OpenStreetMap }\end{array}$ & Export & Yes & Yes & & & &.$c s v$ \\
\hline Scenic Map & $\begin{array}{l}\text { Online image or cached } \\
\text { synthetic (online for whole } \\
\text { world) }\end{array}$ & Import/Export & & & & & $\begin{array}{l}\text { Attached to } \\
\text { waypoints }\end{array}$ & GPX \\
\hline FieldMove & $\begin{array}{l}\text { Online (MapBox) or import } \\
\text { GeoTIFFs, osgEarth, or MBTile } \\
\text { files }\end{array}$ & Import/Export & Yes & Yes & $\begin{array}{l}\text { Yes - and draw } \\
\text { on maps }\end{array}$ & $\begin{array}{l}\text { Yes, georeferenced } \\
\text { images with drawing on } \\
\text { images }\end{array}$ & $\begin{array}{l}\text { Yes, georeferenced } \\
\text { notes }\end{array}$ & .csv, .mve, .kmz \\
\hline Geofieldbook & & & $\begin{array}{l}\text { Record, does not } \\
\text { take using onboard } \\
\text { sensors }\end{array}$ & & Yes & $\begin{array}{l}\text { Yes, georeferenced } \\
\text { images. }\end{array}$ & &.$c s v$ \\
\hline
\end{tabular}




\section{Topo Maps}

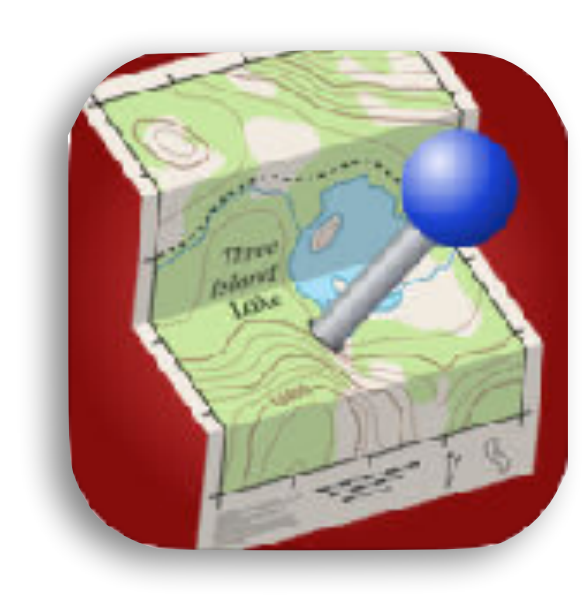

Phil Endecott topomapsapp.com $\$ 7.99$

Waypoints, tracks, viewsheds, distance rings, shaded topography, lighting angle, change waypoint symbol, view waypoints in other apps

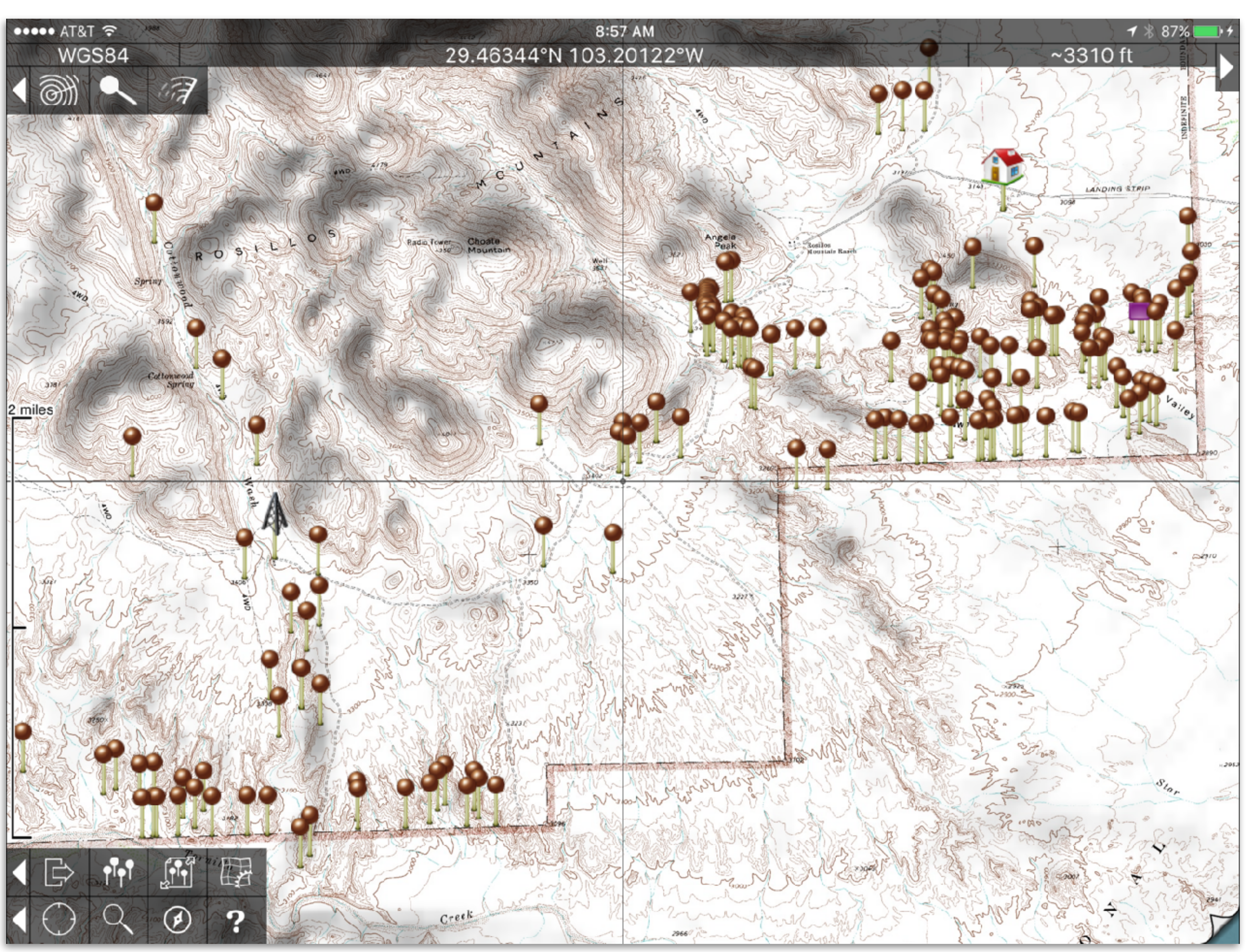




\section{iHike GPS}

James Associates, Inc. ihikegps.com $\$ 9.99$

Waypoints, tracks, topographic profiles

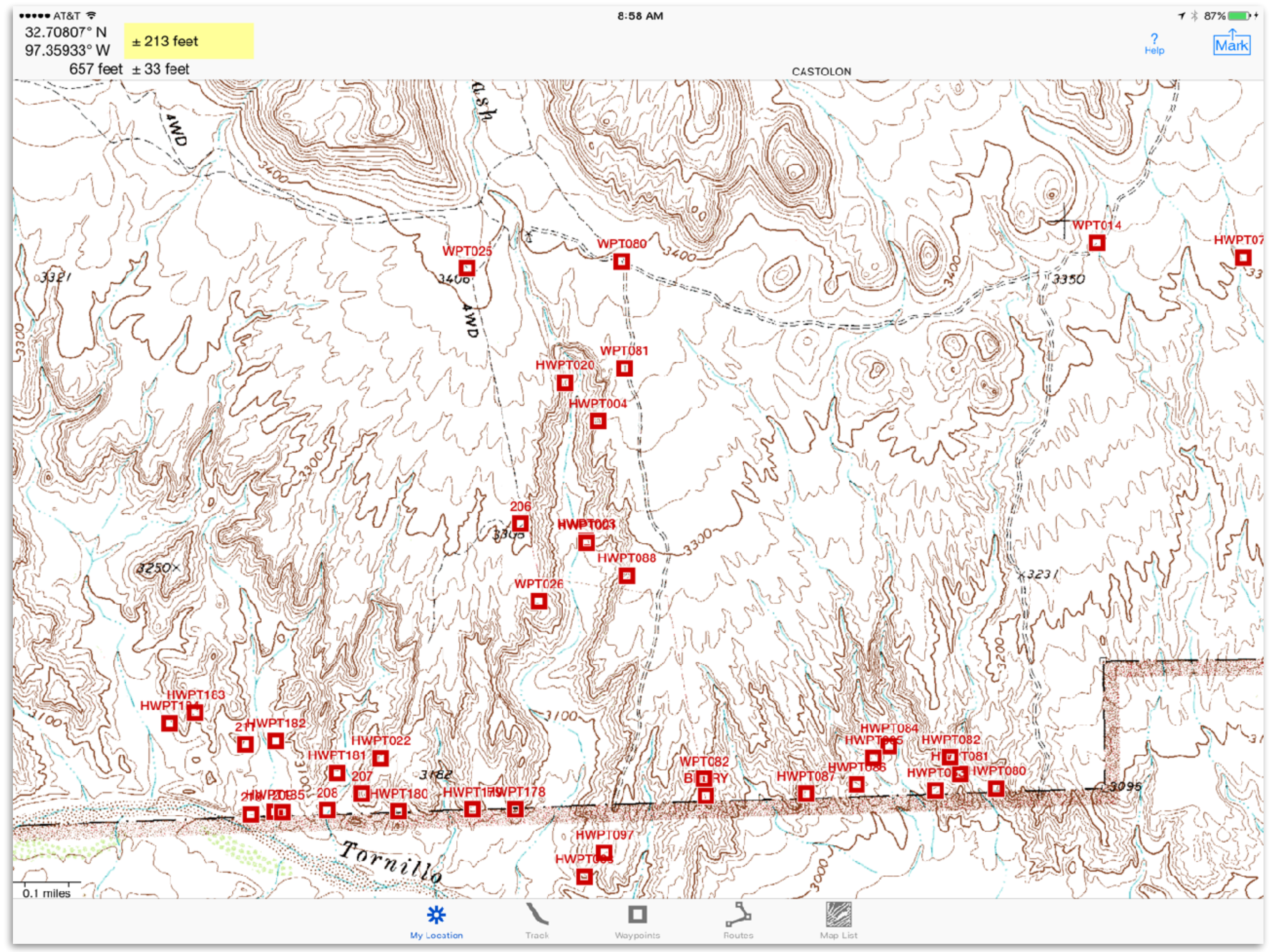




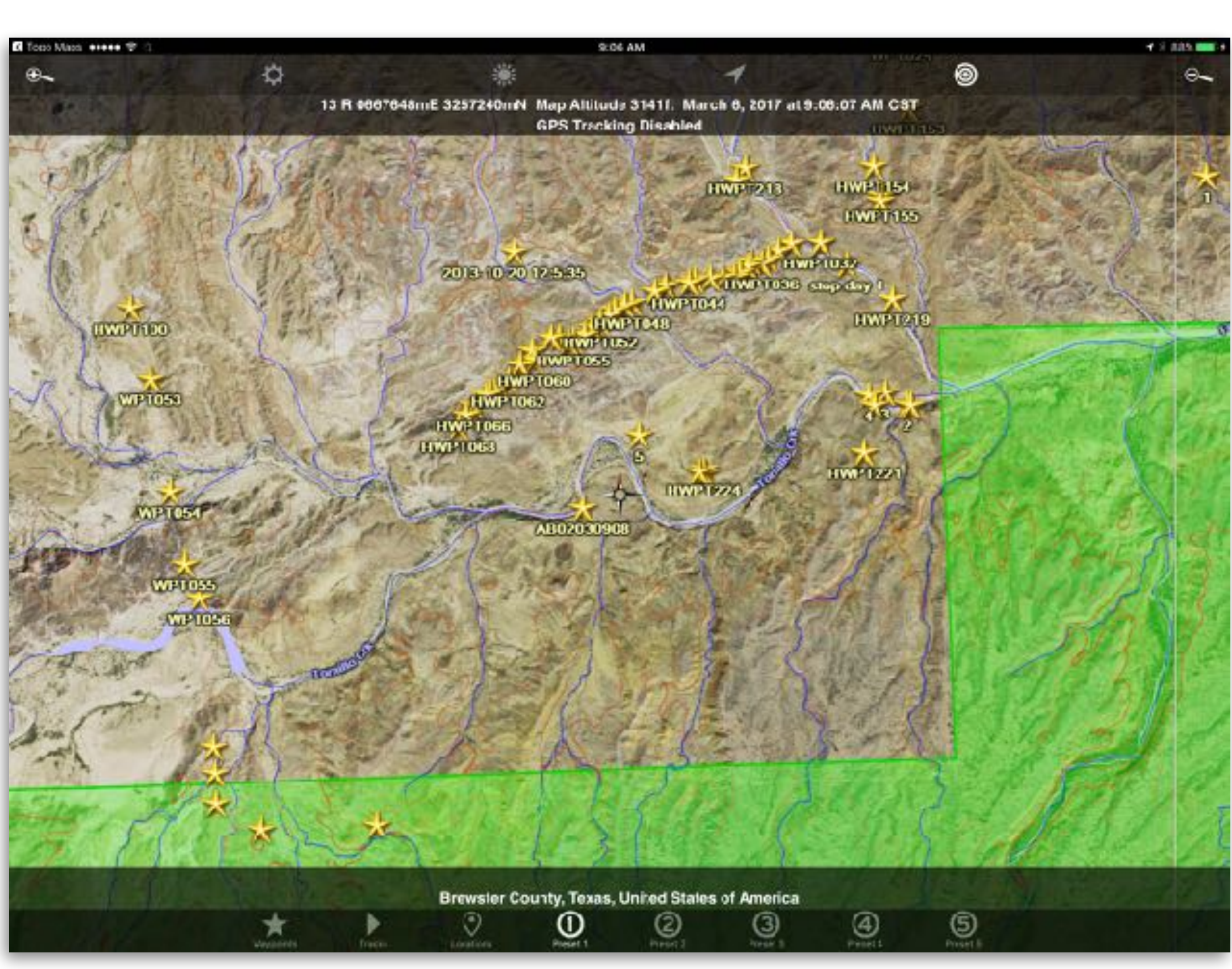

2D - online (above) - offline synthetic below

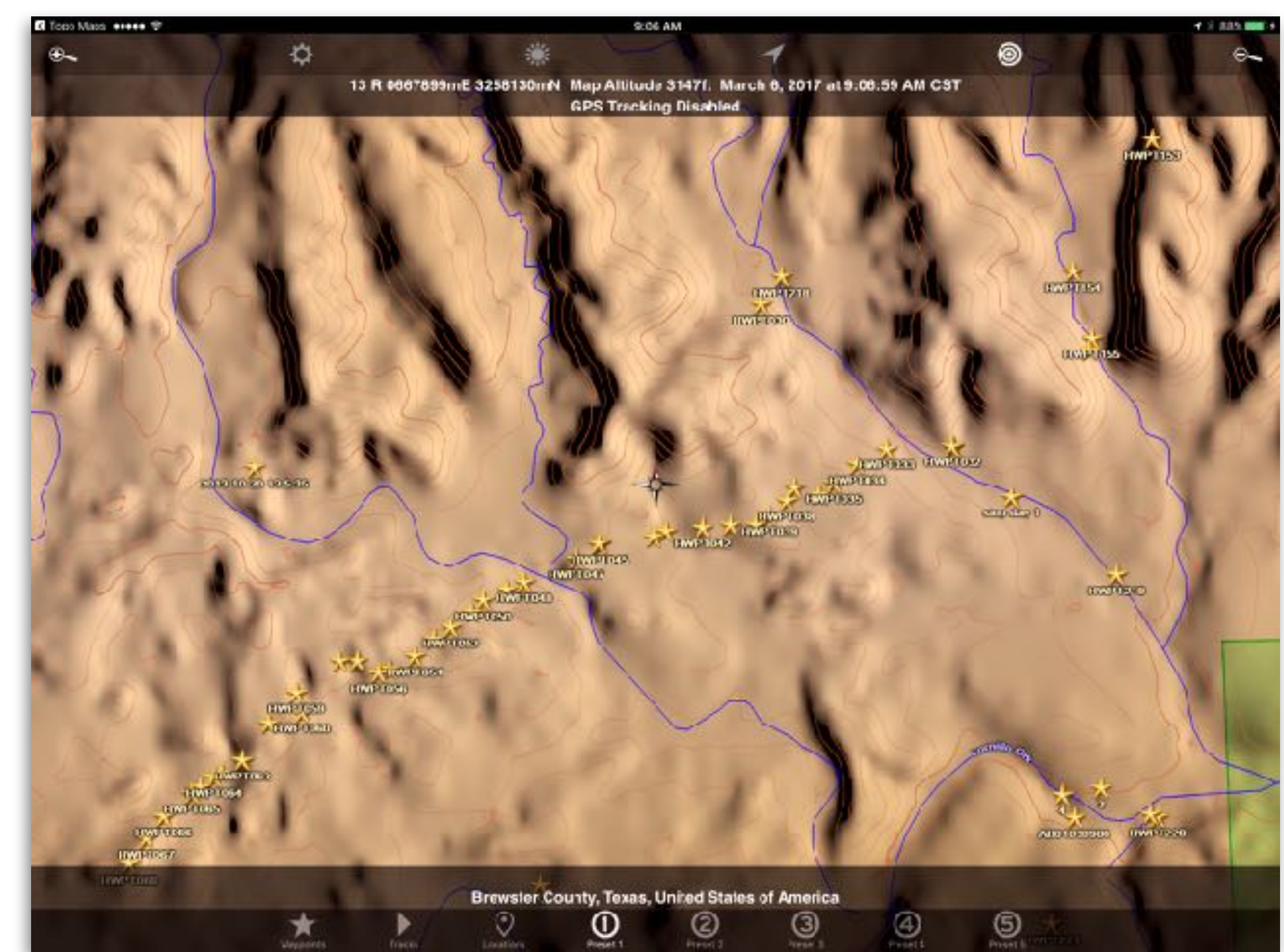

Scenic View

GrangerFX

scenicmap.blogspot.com $\$ 9.99$

Waypoints, tracks, online satellite imagery, off line synthetic maps (see lower pictures) with adjustable color themes. Many different data layers can be viewed.

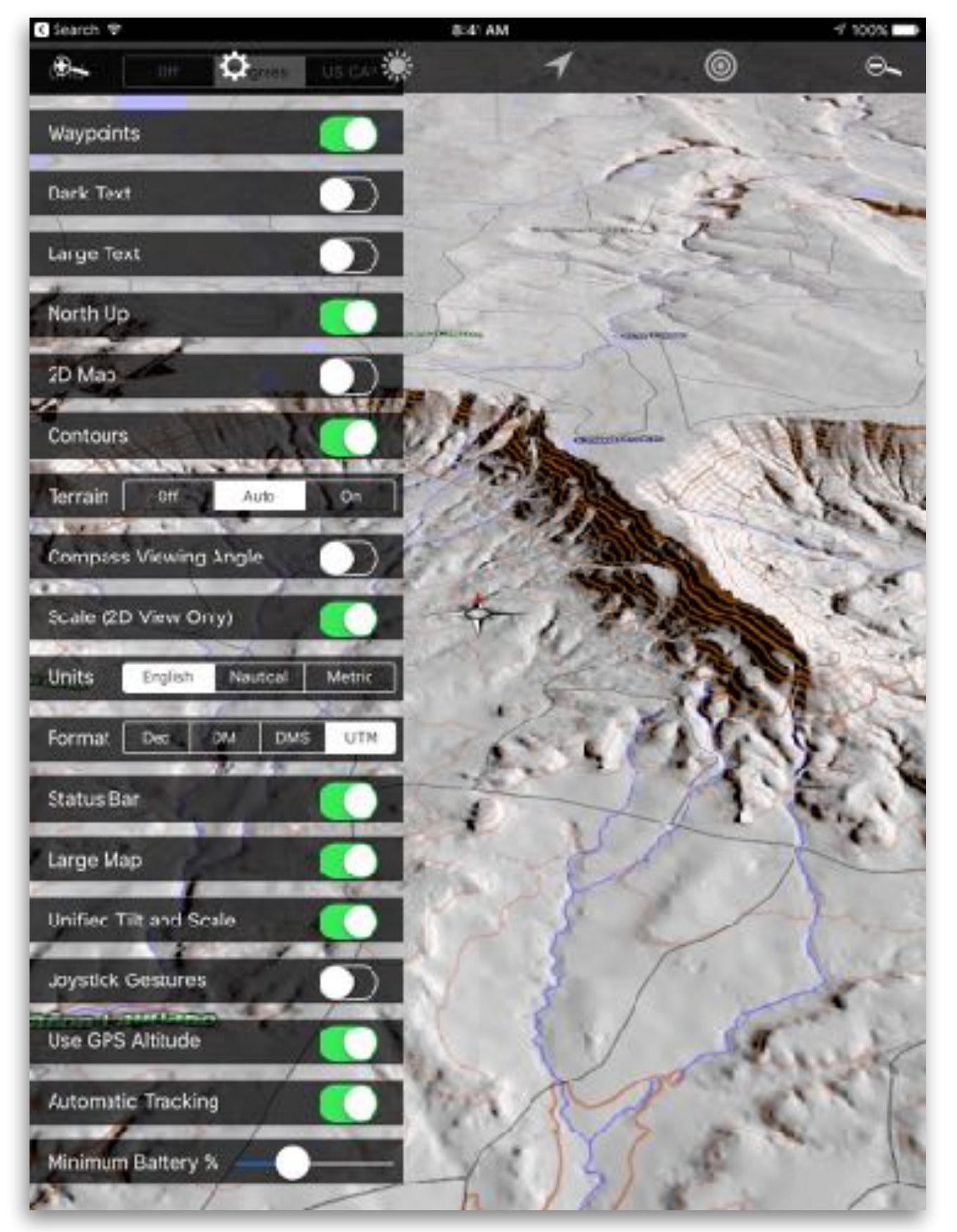

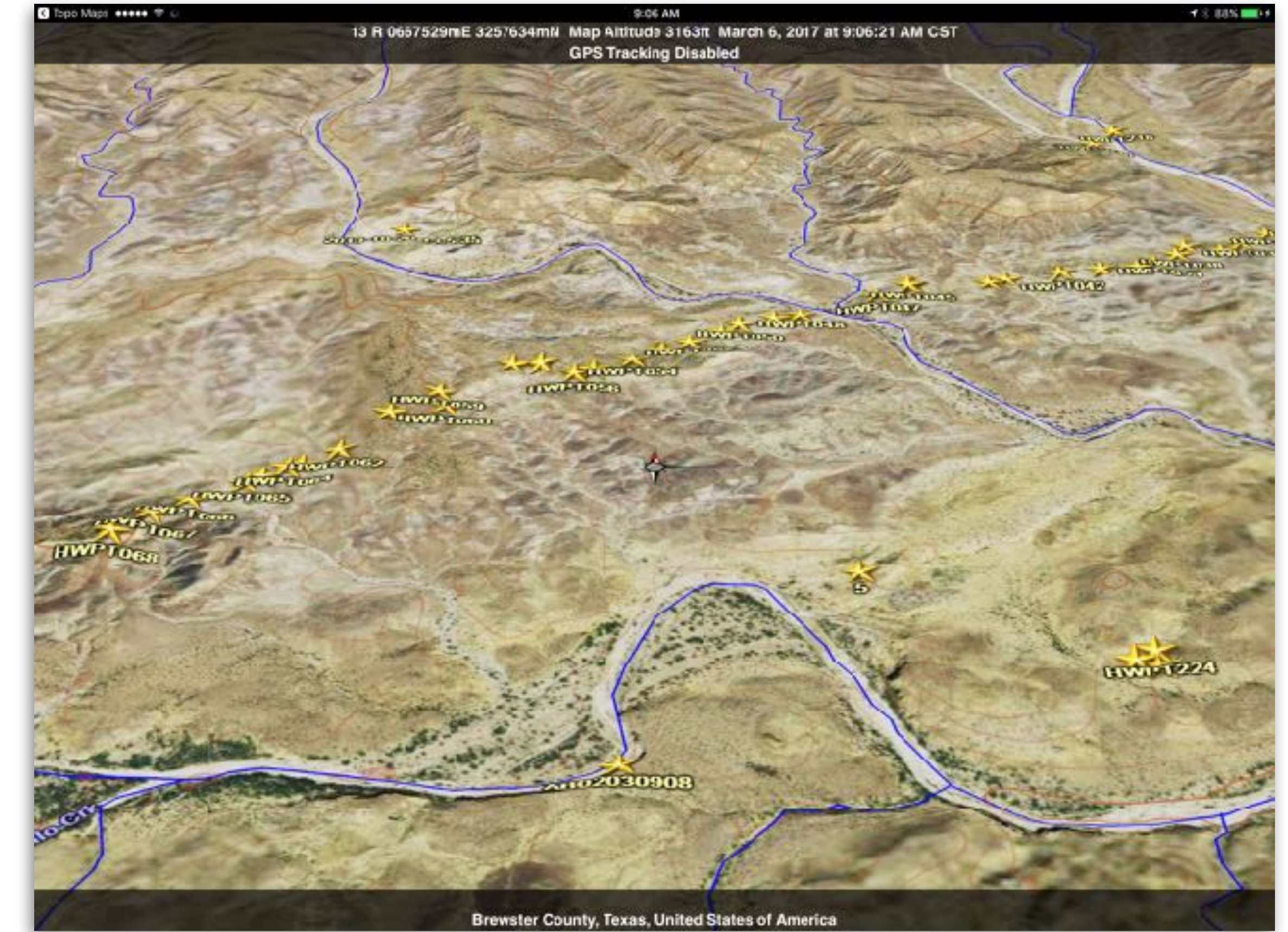

3D - online (above) - offline synthetic below

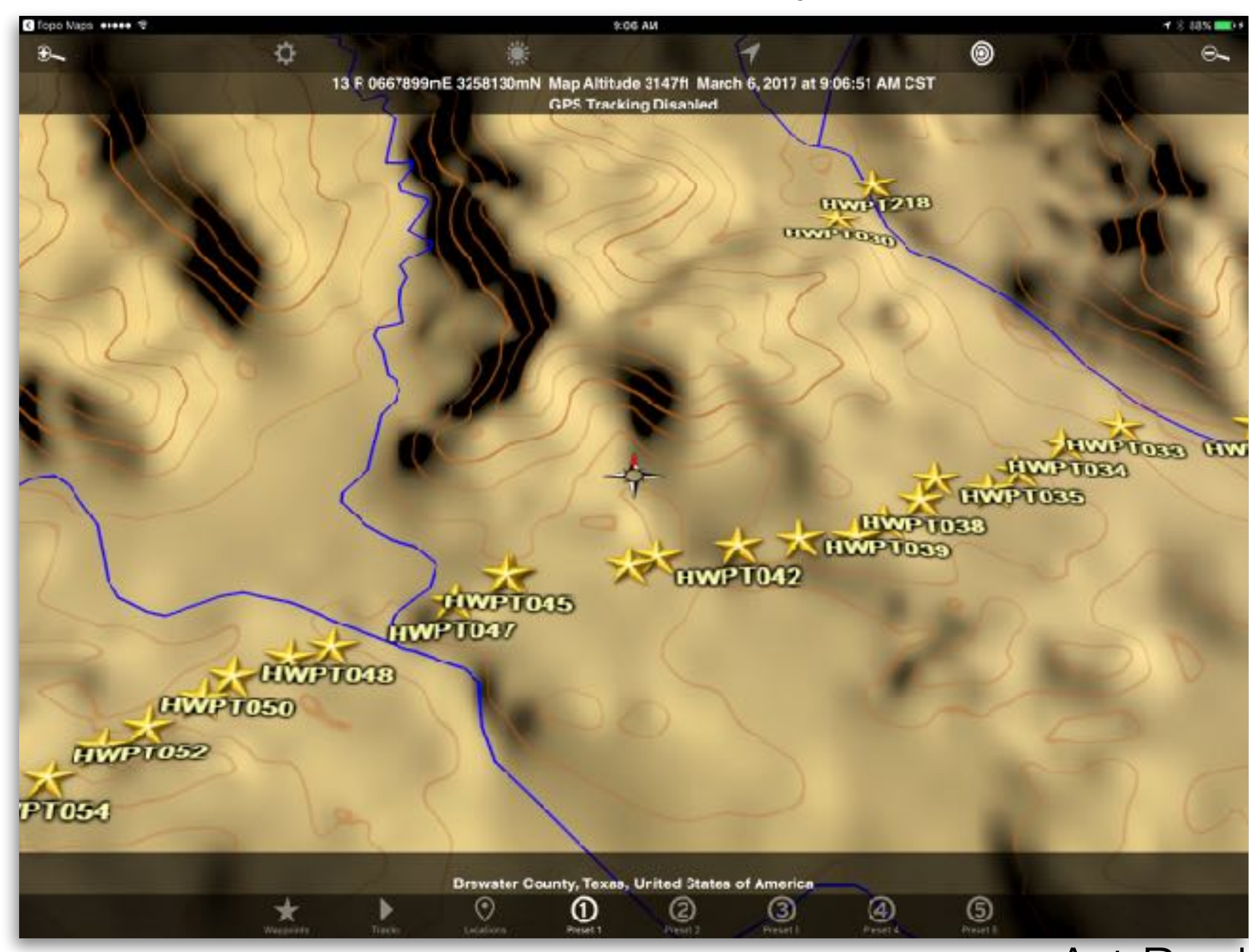




\section{Lambert}

- 0000 T-Mobile Wi-Fi $\widehat{\widehat{ }} \quad$ 10:50 AM

$\checkmark * 99 \%$

\section{Peter Appel}

www.nileus.de/lambert/

$\$ 2.99$

Planar or lineation, Change color, add notes to each control point, stereonet, rose or joint diagrams
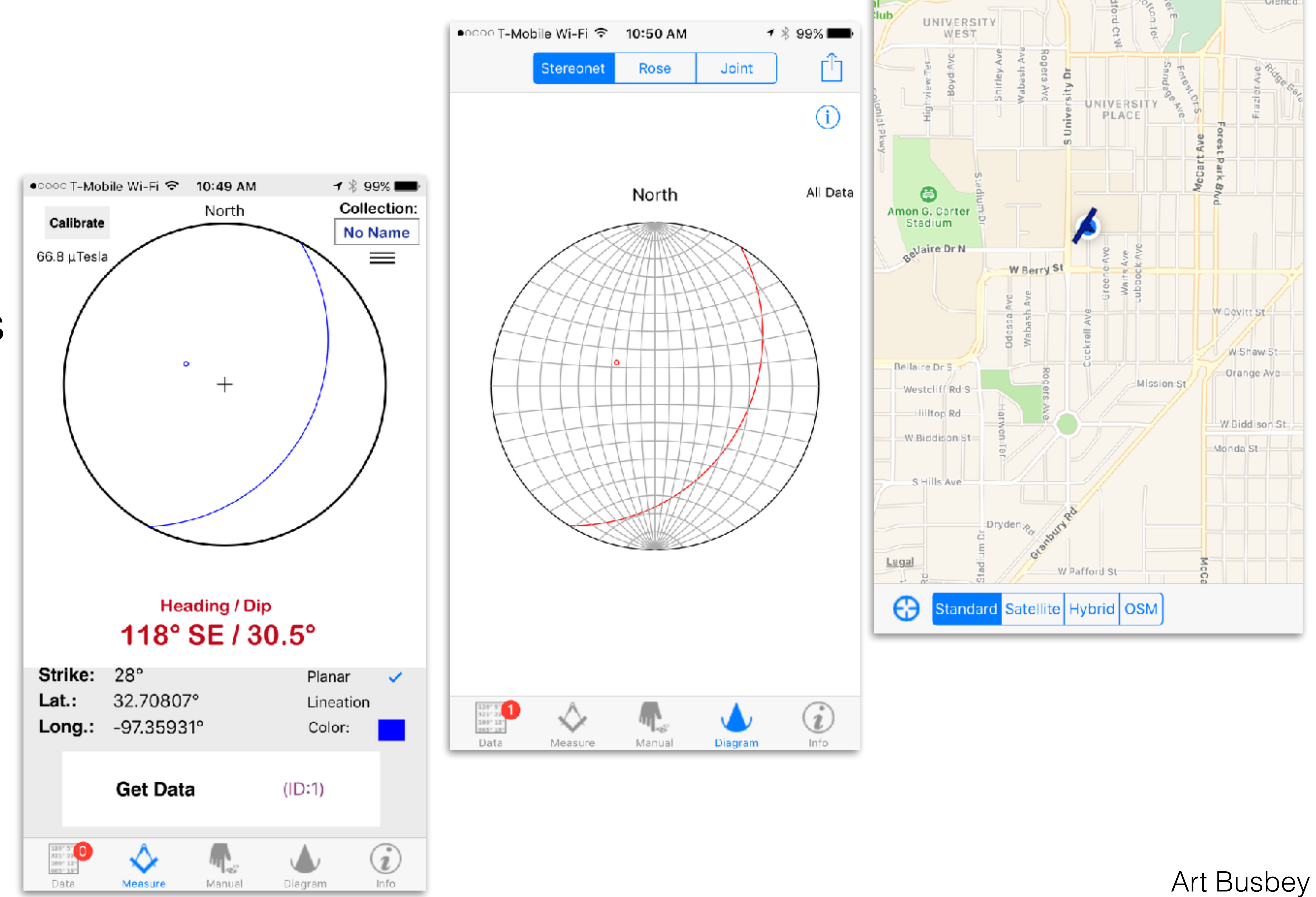

Strike: $28^{\circ}$

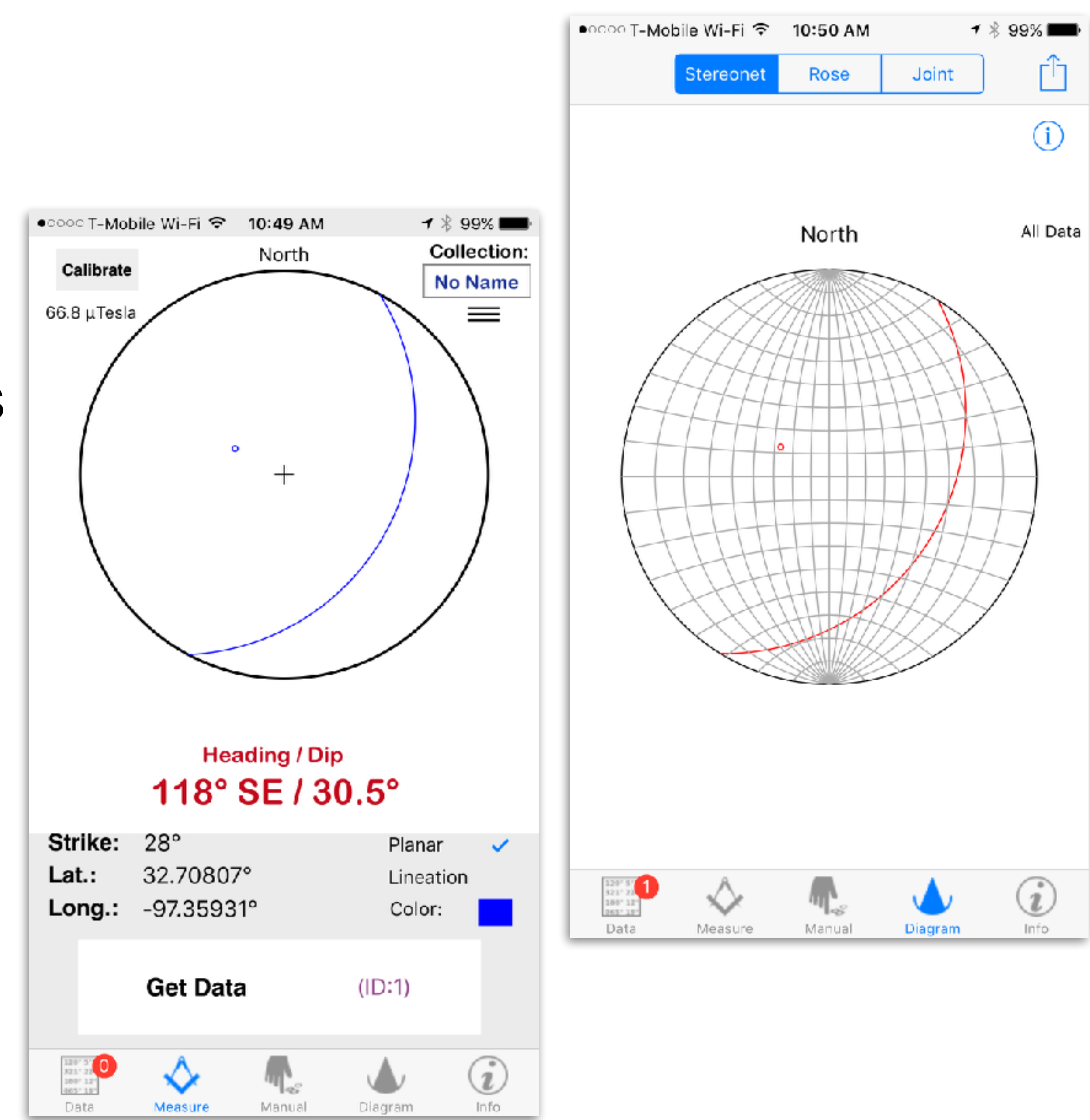

(†) Standard Satellite Hybrid OSM 


\section{GAIA GPS}

Gaia GPS

iOS, Apple watch, Android gaiagps.com

Waypoints, tracks, topo profiles along tracks, easy to cache available online maps, cache custom maps through TMS, in-app subscription to GaiaPro (much larger library of maps that can be locally cached and polygons)

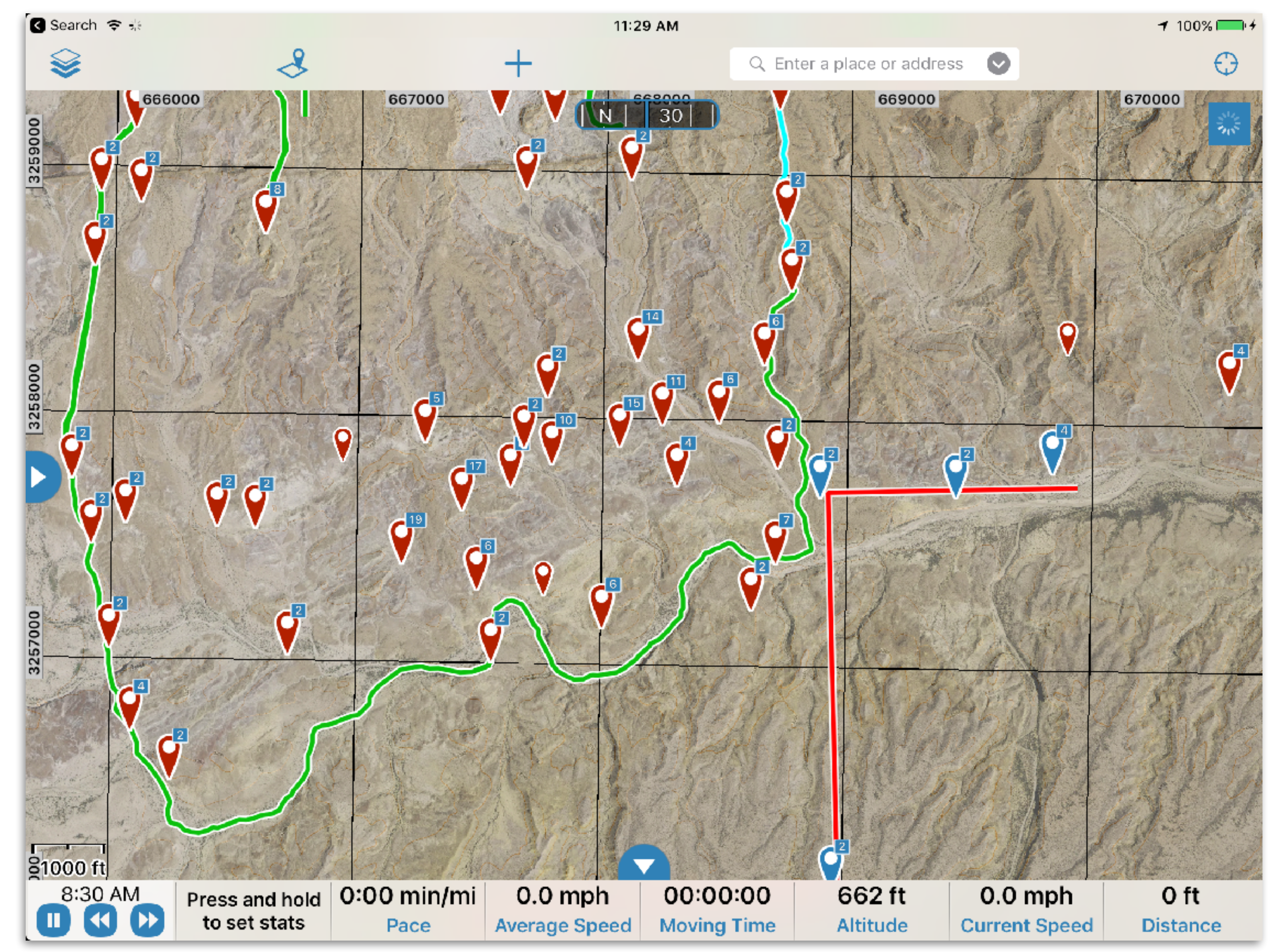




\section{FieldMove Pro}

Midland Valley

https://www.mve.com/digitalmapping

\$30 (add Pro version \$5)

Cache custom maps in MBtiles, GeoTIFF, osgEarth formats, stratigraphic data base, record georeferenced notes, photos, control points (custom symbols \& stereonets), faults, contacts, etc.

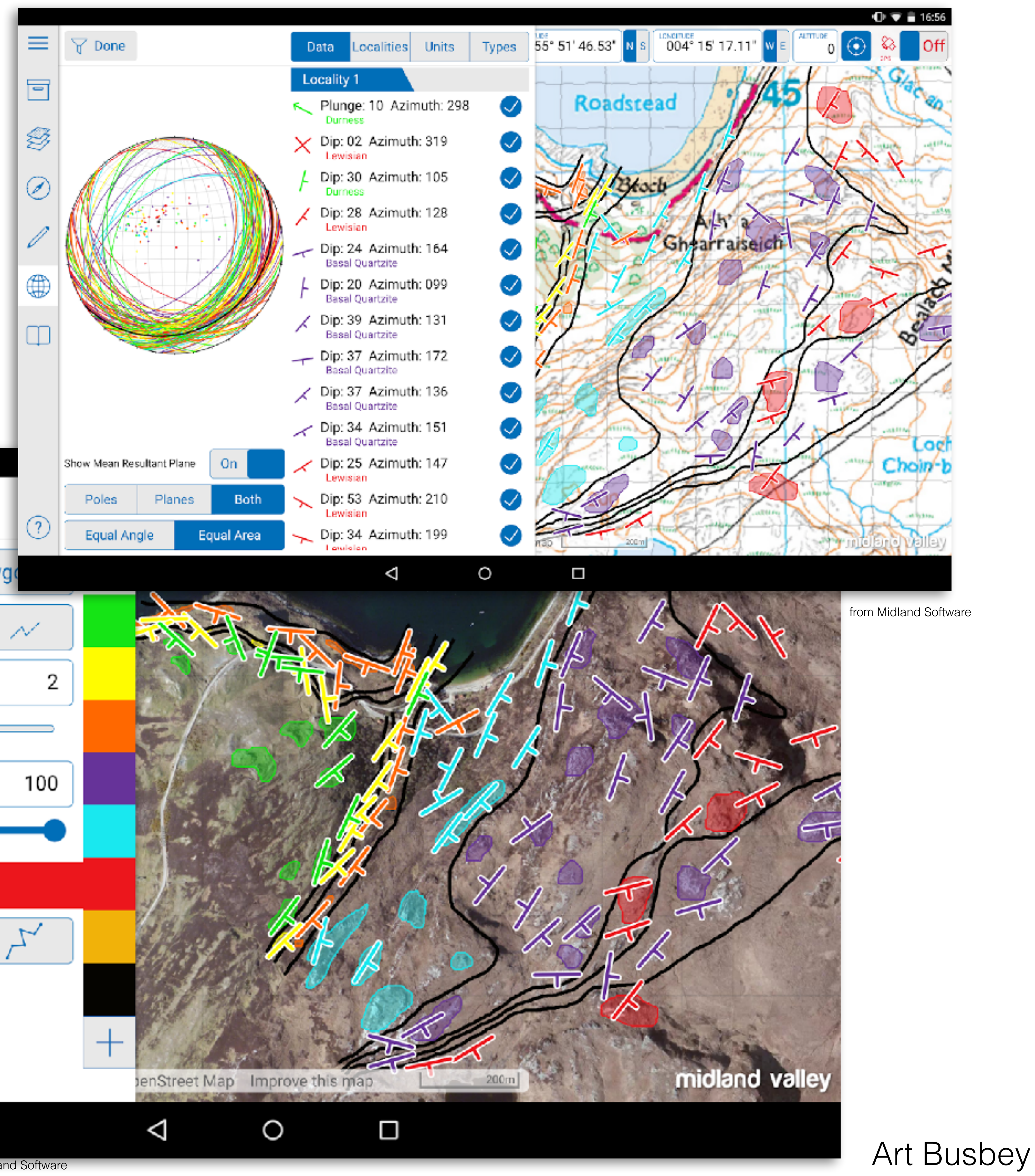


Layered satellite image and USGS topo (using opacity control), with overlaid structural control

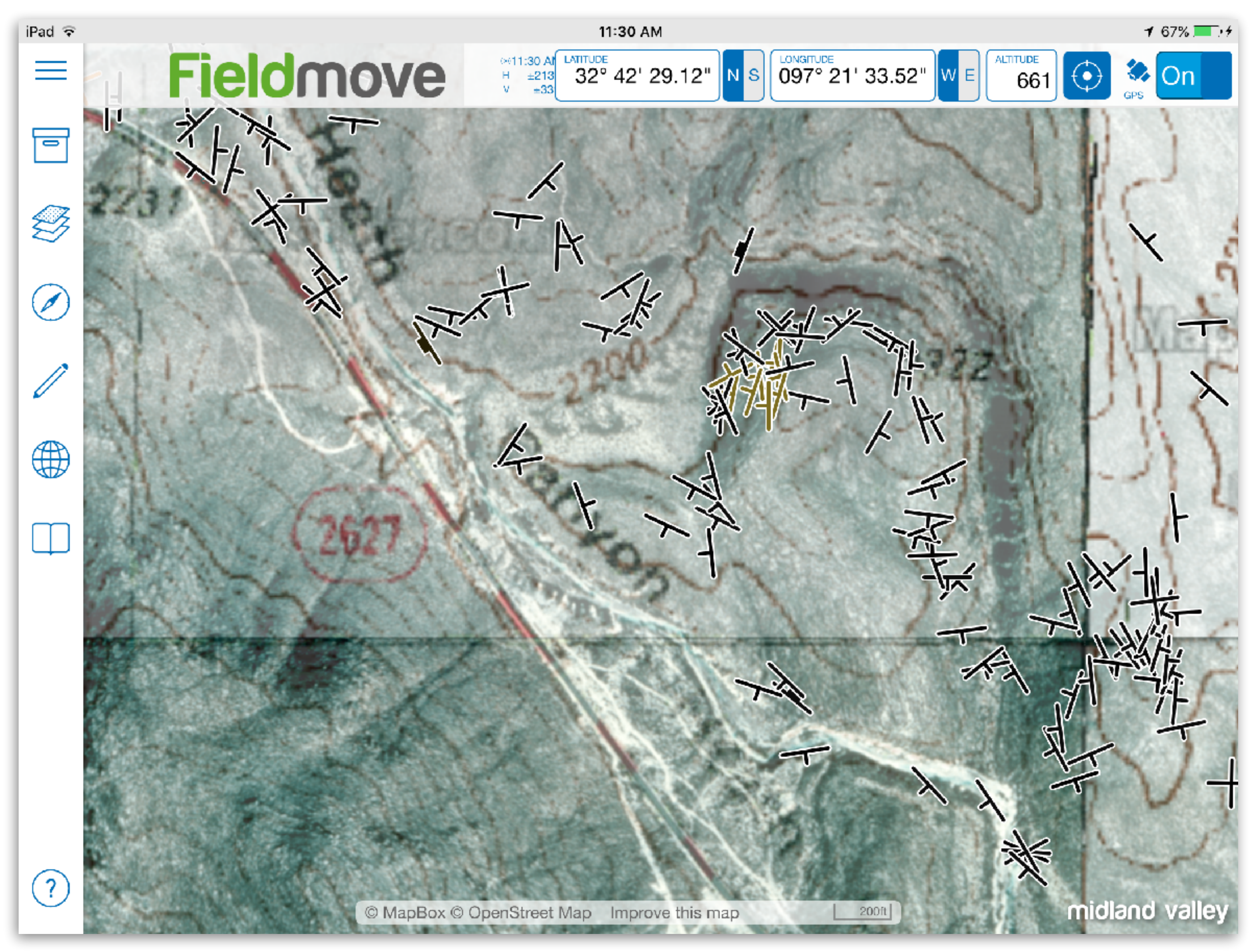

From thesis mapping project, John Williams, Blackgap Wildlife Management Area, Brewster Co., Texas 
Listing of imported maps with controls to view, change opacity, or to pan to image.

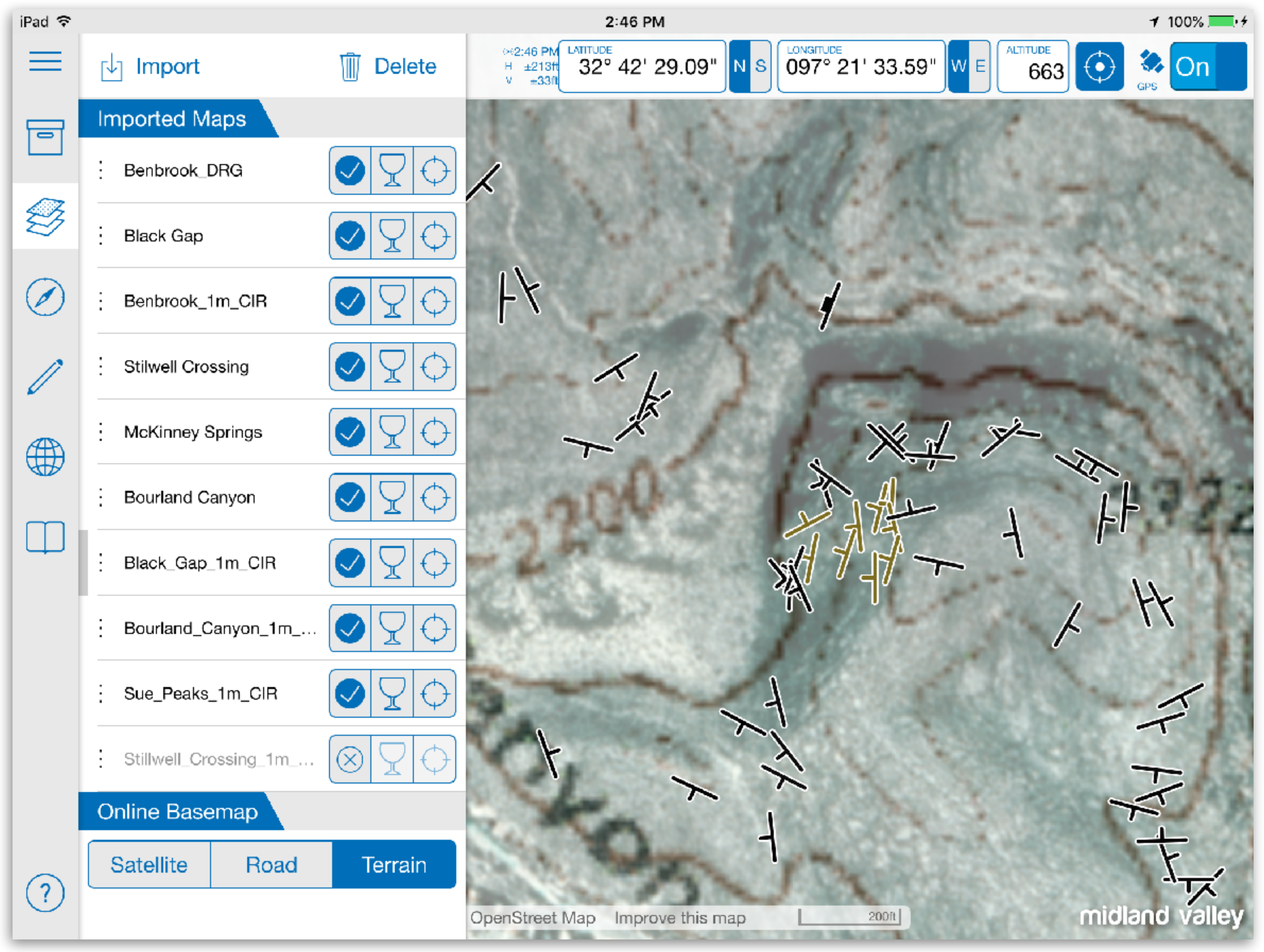


Drafting palette for map with stratigraphic unit selection along right side of edit panel

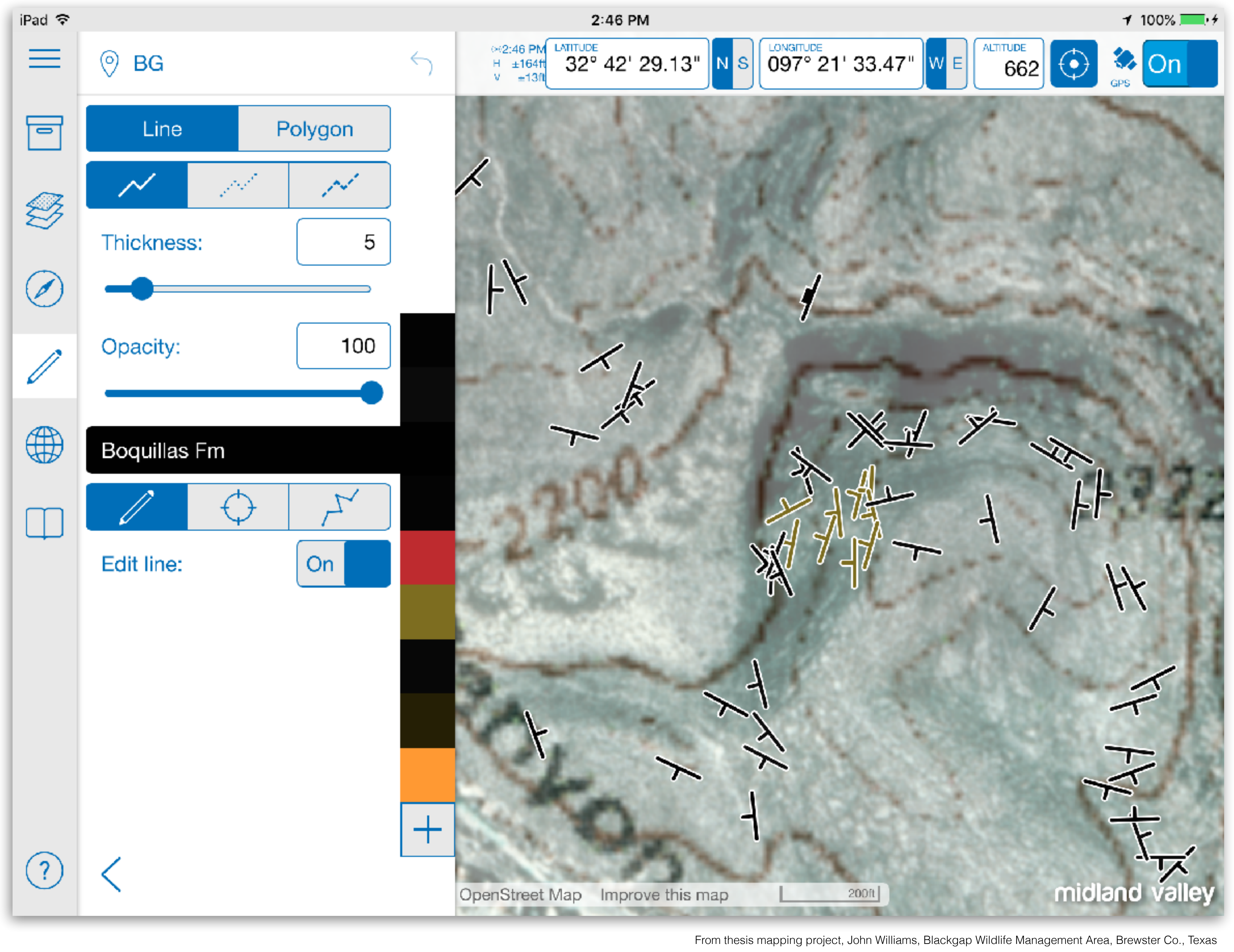

Art Busbey 
Note and picture localities displayed on maps.

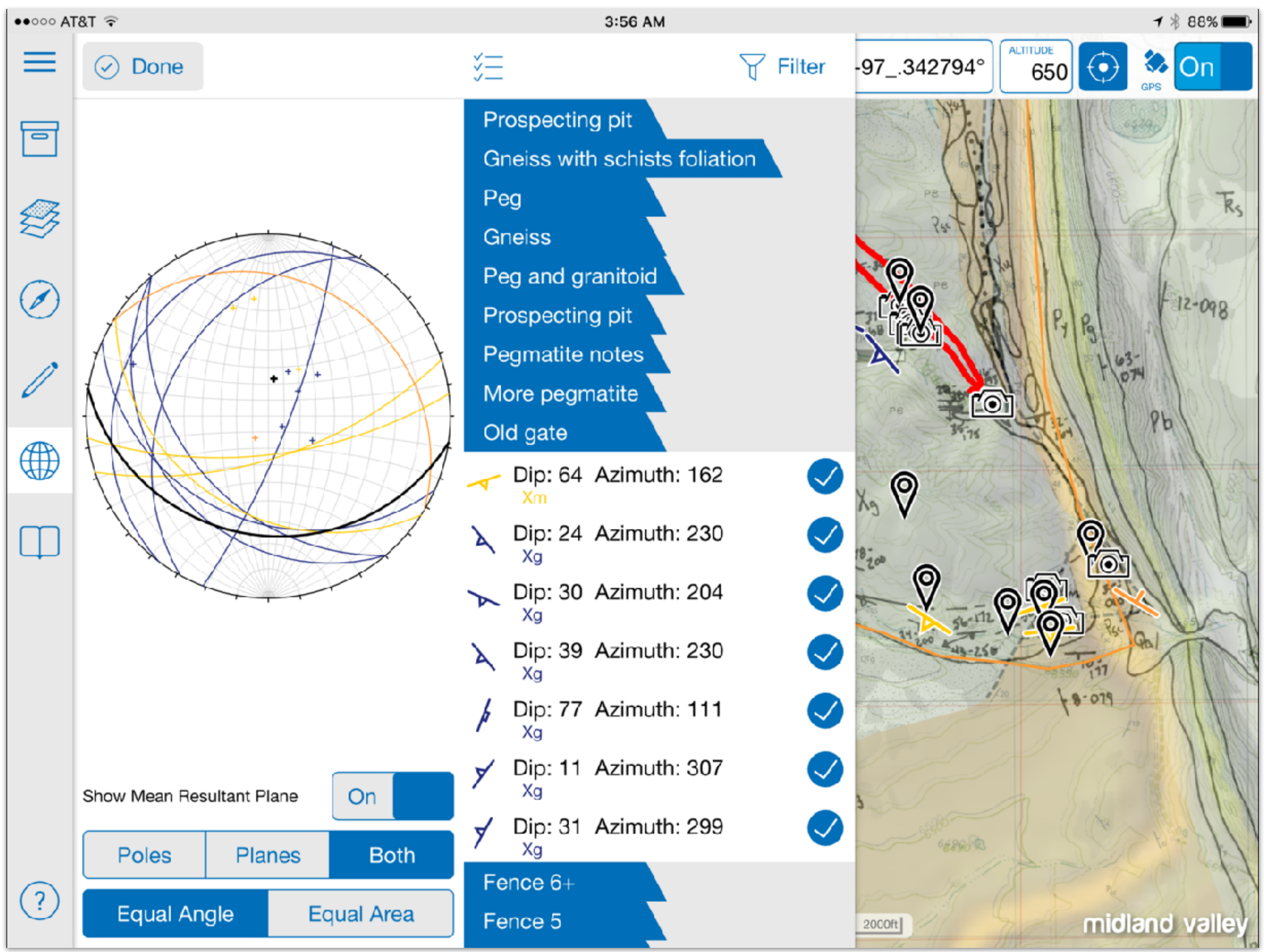

Art Busbey 


\section{iPad FieldMove}

- Leverages platform sensors and ease of use for a tool for collecting data and drafting maps and notes in the field

- Add georeferenced images (with graphic annotations), and notes

- Strike/dip, bearing/plunge with appropriate map symbols plotted on maps and stereonets

- Set up stratigraphic units for drawing outcrop polygons in the field

- Import your own maps in MBTile format or GeoTIFF 


\section{Custom Maps}

- FieldMove imports image MBTiles

- Projects can be exported as a .csv file (comma-separated values), a .mve file (for direct import into Midland Valley's Move software) and a Google Earth .kmz file.

- If GeoTIFFs not available easiest way to generate MBTile files of your custom maps is using the cross platform application - MapTiler 


\section{MapTiler}

- Mac or Windows application for heavy duty lifting, mobile version to view MBtiles

- Georectify maps/images with very easy to use geolocation tool or import rectified images (such as GeoTIFFs)

- Export as MBtiles, KML, etc.

- Free version uses 1 core, staggered costs for versions using more cores and more features

- Klokan Technologies (klokantech.com) 


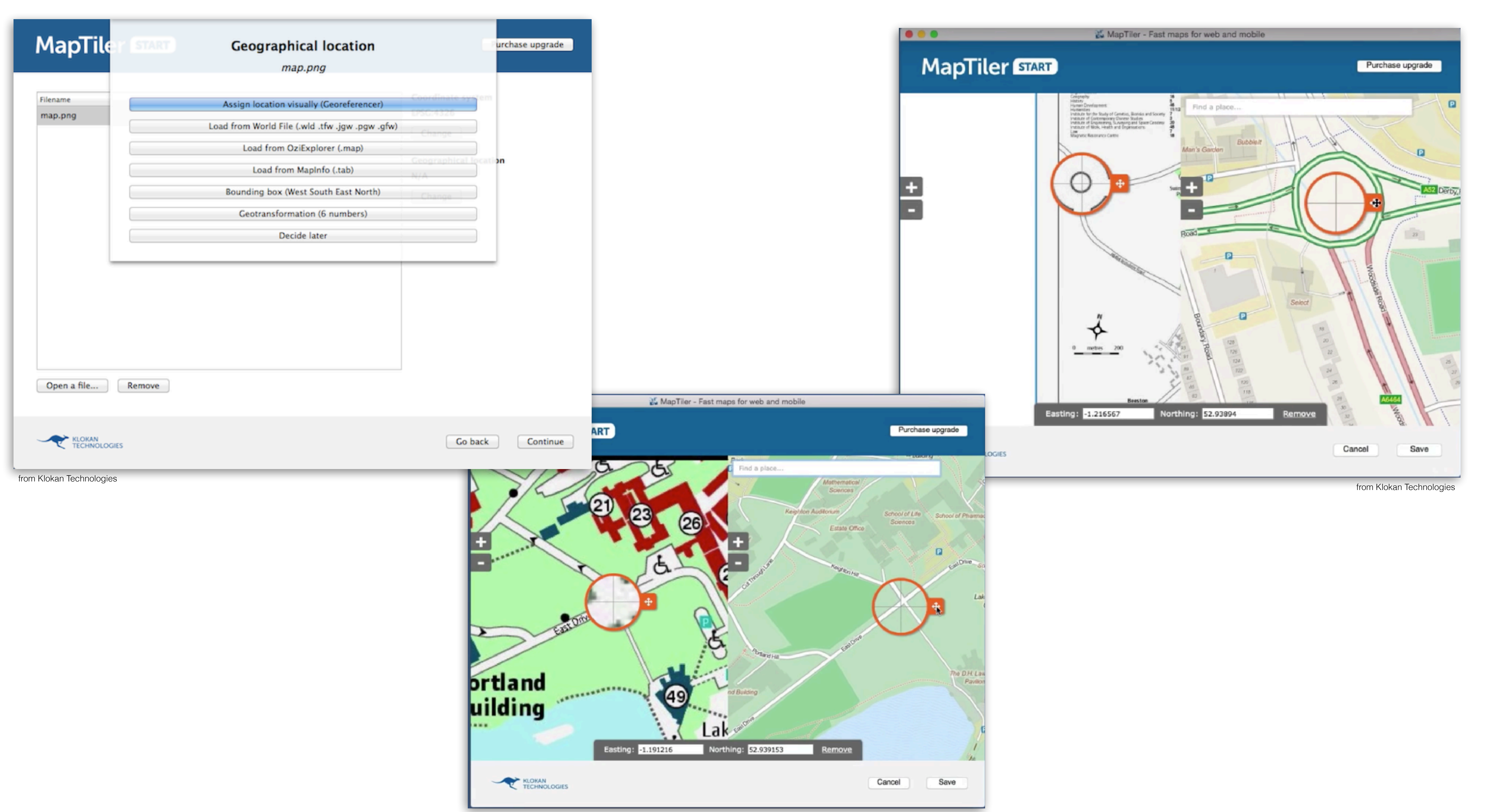




\section{Ipad in the field}

- Excellent tools are available for field mapping

- At the simplest you can record locations as waypoints on maps

- At the most complex complete collection of fieldwork is available

- No matter what solution - archive the data as soon as possible after it is taken 